\title{
PROGRAMA PARA PAIS DE BEBÊS DE RISCO: CONTRIBUIÇÃO PARA FORMAÇÃO DO ALUNO DE ENFERMAGEM
}

\author{
PROGRAM DESIGNED FOR PARENTS OF HIGH-RISK NEWBORNS: A CONTRIBUTION \\ TONURSING EDUCATION
}

\author{
PROGRAMA DIRIGIDO A LOS PADRES DE BEBÉS DE RIESGO: CONTRIBUCIÓN A LA \\ FORMACIÓN DEL ALUMNO DE ENFERMERÍA
}

\author{
Carmen Gracinda Silvan Scochi ${ }^{1}$ \\ Fernanda dos Santos Nogueira ${ }^{2}$ \\ Fabíola Lima Pereira ${ }^{2}$ \\ Mariana Ribeiro Brunherotti
}

\begin{abstract}
RESUMO: Trata da formação acadêmica de alunas de enfermagem inseridas em programa de extensão dirigido aos pais de bebês assistidos em unidades neonatais, objetivando analisar a contribuição desta vivência na formação profissional. Estudo descritivo, tendo como sujeitos alunas, de 18 a 22 anos, que desenvolvem atividades lúdico-pedagógicas e de lazer junto aos pais de bebês de risco assistidos em um hospital escola de Ribeirão Preto. Os dados foram coletados através de um questionário no qual discorreram sobre a vivência no projeto (vantagens, desvantagens e contribuição para a formação profissional). As respostas foram analisadas utilizandose a técnica de análise temática. Verificou-se que a participação no programa ampliou a visão das graduandas sobre o cuidado de enfermagem, possibilitou melhoria no relacionamento interpessoal e no desenvolvimento de habilidades, expandiu a visão da assistência hospitalar para além da doença e proporcionou a aquisição de conhecimentos e valores, contribuindo para a formação acadêmica, estimulando a criatividade.

PALAVRAS-CHAVE: assistência aos pais, formação profissional, enfermagem neonatal
\end{abstract}

ABSTRACT: The present study is related to the academic education of nursing students who participated in a public service program designed for parents of high-risk newborns assisted in neonatal units. It is a descriptive study that has as its objective to analyze the contribution of such professional experience for those students. The subjects of this investigation were nursing students aged 18 to 22 years old. These students performed ludic, educational and leisure activities with parents of high-risk newborns assisted in a university school in the city of Ribeirão Preto. Data were collected by means of a questionnaires through which the subjects reported their experience in the project (advantages, disadvantages and contributions to their education). The answers were analyzed through the thematic analysis technique. Results showed that the program expanded students' view concerning nursing care and hospital care (beyond disease). It also improved interpersonal relationships; promoted the development of skills and the acquisition of knowledge and values. Thus contributing to students' academic education and creativity.

KEYWORDS: care to parents, professional education, neonatal nursing

RESUMEN: Trata de la formación académica de alumnas de enfermería que realizan un programa de extensión dirigido a los padres de bebés asistidos en unidades neonatales, con el fin de analizar la contribución de esa vivencia/experiencia en la formación profesional. Estudio descriptivo, cuyos sujetos son las alumnas, de 18 a 22 años, quienes desarrollan actividades lúdico-pedagógicas junto a los padres de bebés de riesgo asistidos en un hospital escuela de Ribeirão Preto. Los datos se colectaron a través de un cuestionario en el cual hablaron sobre dicha experiencia(ventajas, desventajas y contribución para la formación profesional). Las respuestas se analizaron utilizándose la técnica de análisis temático. Se verificó que la participación en el programa amplió la visión de las alumnas sobre el cuidado de enfermería, posibilitó mejoria en el relacionamiento interpersonal y en el desarrollo de habilidades, amplió la visión de asistencia hospitalaria más allá de la enfermedad y proporcionó la adquisición de conocimientos y valores, que contribuyen asi para la formación académica y estimulan la creatividad. PALABRAS CLAVE: asistencia a los padres, formación profesional, enfermería neonatal

Recebido em 29/11/2001 Aprovado em 06/02/2002

\footnotetext{
${ }^{1}$ Professora Associada do Departamento de Enfermagem Materno-Infantil e Saúde Pública - EERP-USP.

2 Alunas do Curso de Graduação da EERP-USP.
} 


\section{INTRODUÇÃO}

O ensino de enfermagem, composto por formação geral, funções assistenciais e educativas, é instrumento básico na saúde, sendo largamente enfatizado na formação de enfermeiros (COSTA, 1993). A formação do aluno de graduação, a cada dia, tem-se ampliado através da inserção em atividades de pesquisa e serviços de extensão à comunidade. Tradicionalmente o ensino de enfermagem tem se baseado em aulas teóricas, práticas em laboratório e estágios vinculados às disciplinas. Entretanto, com a nova perspectiva de mercado que tem requerido um profissional criativo, com conhecimento atualizado, esta metodologia de ensino tornou-se ultrapassada e é neste cenário que a diversidade de atividades acadêmicas começam a fazer parte da vida estudantil e da formação do aluno.

De acordo com Jorge, (1997), ensinar não é apenas transmissão de informação teórica, mas também instigar a criatividade, a habilidade de comunicação e a criação de espaços para que o aluno possa se desenvolver com liberdade.

Almeida ${ }^{3}$ considera que a atividade acadêmica envolve o ensino, a pesquisa e a extensão de serviço à comunidade. No desenvolvimento desta prática, os docentes têm se organizado em grupos de estudo e pesquisas, nos quais se inserem profissionais do serviço, alunos de graduação e pós-graduação. Muitos destes grupos possuem projetos de extensão de serviços à comunidade, alguns funcionando como laboratórios sociais, enquanto campo de formação e capacitação de recursos humanos e de desenvolvimento de investigação cientifica.

A pesquisadora considera ainda, que para o desenvolvimento de conhecimento técnico e científico é imprescindivel que o aluno se insira em atividades de pesquisa durante a formação acadêmica para assegurar a interdependência da pesquisa, do ensino e da extensão de serviço à comunidade, cujas atividades sustentam o tripé dos principios fundamentais da arte e ciência da Enfermagem.

Atuando na docência na área de Enfermagem Neonatal, implantamos um programa de intervenção envolvendo atividades lúdico-pedagógicas e de lazer junto aos pais de bebês de risco assistidos nas unidades neonatais do Hospital das Clínicas de Ribeirão Preto (HC/RP), cuja programação operacional é desenvolvida por alunos de graduação em enfermagem (SCOCHI et al., 1999).

O projeto foi criado a partir da nossa experiência profissional, na qual percebemos que no processo de trabalho em berçários, a enfermagem depara-se também com as necessidades dos pais, apresentando sentimentos de medo, culpa, dentro outros, e necessitando de apoio e treinamento para o cuidado do filho.

Inicialmente, o projeto foi discutido com as enfermeiras das unidades neonatais do HC/RP, procurando-se sensibilizá-las sobre a importância do projeto, na perspectiva de ampliação do modelo de atenção vigente, em especial a assistência de enfermagem centrada na família. As enfermeiras também opinaram sobre a programação elaborada, bem como sobre o melhor horário e local para a realização das atividades, em função do envolvimento das mães no cuidado do filho (BRUNHEROTTI et al., 2000).

Entendemos que a formação dos graduandos deve ser expandida através da participação deles em atividades extracurriculares. Assim, motivamo-nos realizar o presente estudo esperando elucidar a contribuição da participação em programas criativos de extensão de serviços à comunidade, na perspectiva da formação acadêmica dos alunos de enfermagem.

\section{OBJETIVO}

Analisar a contribuição da vivência dos graduandos de enfermagem, em um projeto de extensão de serviços à comunidade dirigido aos pais de bebês de risco assistidos em unidades neonatais, na perspectiva da formação profissional.

\section{METODOLOGIA}

O programa de intervenção foi implantado em março de 1999, sob nossa coordenação, e desenvolvido operacionalmente por cinco alunas de graduação em enfermagem.

Teve como locus institucional um hospital escola, público, de porte especial e de referência terciária para assistência perinatal e em outras especialidades. Dispõe de 40 leitos neonatais, sendo 16 para o cuidado intensivo e 24 para o intermediário.

As atividades junto aos pais, em especial às mães por estarem mais presentes no berçário, são realizadas semanalmente, com duração máxima de 2 horas. As reuniões com o grupo de pais constam de três momentos: primeiramente faz-se a apresentação dos participantes e objetivos do grupo; em seguida realiza-se técnicas de dinâmica de grupo

${ }^{3}$ ALMEIDA, M.C.P. Prática de enfermagem na atenção primária de saúde: a experiência do Departamento de Enfermagem Materno-Infantil e Saúde Pública da Escola de Enfermagem de Ribeirão Preto - Universidade de São Paulo - Brasil, julho de 2000. Comentário pessoal. 
(teia feita de barbante, técnica da bexiga, bio-dança, queda de confiança - pêndulo, caminhada de confiança - "olhos vendados"; corrida de confiança, sentindo a face, Cosme e Damião), visando aliviar tensões e propiciar oportunidades de lazer e, finalmente, são realizadas oficinas de criatividade através do desenvolvimento de trabalhos manuais ou discussão de temas básicos para o auto-cuidado e cuidados com o ambiente domiciliar (BRUNHEROTTI et al., 2000).

Mensalmente realiza-se reunião entre as alunas responsáveis pela execução das atividades e a coordenadora do projeto, visando ao acompanhamento sistemático da programação, avaliação das vivências e reestruturação das estratégias de intervenção. Por ocasião do início da implantação do programa, contava-se com a assessoria de um enfermeiro da área de saúde mental, com ampla experiência em expressão corporal e dinâmicas de interação grupal. Para atender ao objetivo do presente estudo, utilizamos como sujeitos as cinco alunas de graduação $(\mathrm{A} 1, \ldots, \mathrm{A} 5)$ da Escola de Enfermagem de Ribeirão Preto da Universidade de São Paulo (EERP-USP), as quais estavam matriculadas no primeiro, segundo, terceiro (duas alunas), e quarto ano do curso de graduação em enfermagem em idade variando entre 18 a 22 anos .

A coleta de dados foi feita após assinatura de consentimento pós-informado e realizada através de um questionário auto-aplicável, contendo dados de identificação e o seguinte direcionamento: "Comente sobre sua vivência no projeto: vantagens, desvantagens e importância para a formação profissional".

Para análise e interpretação dos dados, utilizamos parte da técnica de análise de enunciação proposta por Laurence Bardin (1977), ou seja, apenas a primeira etapa - a análise temática. A análise de enunciação é uma das propostas para a análise de conteúdo, fundamentada na concepção da comunicação como processo e não como um dado estanque, desviando-se das estruturas e dos elementos formais da análise de linguagem.

Para a preparação do material a ser coletado, seguimos os passos propostos pelo autor, adaptados à realidade do estudo:

- transcrição rigorosa do material coletado;

- leitura flutuante do material intercalando, selecionado-se os dados do estudo;

- projetado a grelha de categorias, que optamos por determinar de "temas". Nesta fase de análise, trabalhamos cada entrevista separadamente, recortando os falas (frases) que representam determinado tema. Para facilitar a compreensão dos destaques nas falas, optamos pela seguinte padronização ou legenda:

I_/ recortes de outras falas, ... recortes na mesma fala,
( ) observações complementares contendo conteúdos e comportamentos não verbais para situar as falas.

- Na seqüência, para cada tema correlacionamos os núcleos de sentido recortados das falas de todos os sujeitos selecionados na etapa anterior.

\section{RESULTADOS E DISCUSSÃO}

A proposta do programa implantado é a introdução de atividades de lazer junto aos pais de bebês de risco assistidos em unidades neonatais, portanto, não requer das alunas de enfermagem habilidades desenvolvidas na disciplina de Enfermagem Pediátrica e Neonatal, oferecida no $7^{\circ}$ semestre do curso de graduação da EERP-USP. Assim, por ocasião da coleta de

dados, nenhuma das alunas havia cursado a disciplina; três delas envolveram-se no projeto desde a sua organização e implantação.

As manifestações escritas das alunas acerca da importância dessa vivência no projeto foram agrupadas em quatro temas: "ampliando a visão sobre o cuidado de enfermagem", "melhorando o relacionamento interpessoal e o desenvolvimento de habilidades", "assistência hospitalar: para além da doença" e "adquirindo conhecimentos e valores", os quais foram reclassificados em sub-temas, conforme se segue.

\section{TEMA 1 - AMPLIANDO A VISÃO SOBRE O CUIDADO DE ENFERMAGEM}

Este tema emergiu de forma marcante nas respostas emitidas pelas alunas, sendo agregado em três sub-temas: "a importância da humanização do cuidado", "olhando para além do bebê: a familia também tem necessidade de cuidado" e "visão holistica do cuidado".

\section{A importância da humanização do cuidado}

A humanização é fator presente demonstrando o novo rumo que o cuidado à saúde vem assumindo, nos últimos anos.

Acreditamos, conforme expressa Nosseto (1997), que o processo de aprendizagem na enfermagem é contínuo e cria a possibilidade de que este "saber" se transforme em ajudar, dispor dos conhecimentos adquiridos para compreender e atender as necessidades do outro. O autor afirma ainda, que a relação terapêutica só tem sucesso a partir do momento que se estabelece um vínculo significativo com o outro.

Com relação à assistência à criança hospitalizada, Lima (1995) relata que esta tem sofrido 
constantes transformações e tem como meta principal um cuidado mais integralizado. O objeto de trabalho deixa de ser o corpo biológico e passa a ser a criança na sua especificidade. Desta forma, quando o modelo de assistência passa a ser além da cura da doença, a assistência centrada no modelo clínico passa a ser insuficiente.

$\mathrm{Na}$ área de Enfermagem Neonatal, Scochi (1996), analisando as transformações ocorridas na assistência, apreendem que, na última década, o objeto de ação ampliou-se envolvendo o binômio mãefilho, familia e comunidade, bem como o trabalho de uma equipe multiprofissional, tendo como meta a qualidade de vida e humanização do cuidado.

Estes aspectos, de certa forma, foram apreendidos pelas alunas de enfermagem através da vivência no programa de extensão, conforme demonstram os relatos:

... eu pude compreender como a humanização é vital também para a família. (A1)

Para o meu futuro como uma profissional de enfermagem, espero que me ajude a olhar principalmente, o lado mais humano de cada paciente, um pouco além do que aprendemos na faculdade. (A3)

A participação no projeto possibilitou um maior contato com o outro lado do paciente permitindo uma visão mais humanizada no cuidado (...) $A$ humanização do serviço, muitas vezes passa meio desapercebida durante a graduação pois o aluno fica centralizado no cuidado da doença e esquece de olhar o paciente como uma pessoa que além da doença instalada possui uma série de outras necessidades que não devem ser ignoradas (...) É gratificante ouvir do grupo (mães) que as atividades realizadas foram importantes para suas vidas, pois é assim que podemos acreditar que a humanização do serviço é válida. (A5)

\section{Olhando para além do bebê: a família também tem necessidades de cuidado}

A inserção das alunas no programa de extensão possibilitou ampliar a visão acerca do objeto de intervenção, de modo a não se centrar na recuperação biológica do bebê de risco, mas também na familia que tem necessidades especiais e necessita de atenção e cuidado. Esse aspecto da formação profissional expandiu-se para outros contextos e especialidades da prática de enfermagem, conforme demonstram os relatos que se seguem:

Eu observei que as atividades com as mães faziam com que elas se sentissem melhor e conseqüentemente voltassem para o berçário tranqüilas (...) Enquanto pessoa pareipra pensar em como a mãe se sentia, em como ela é frágil, e tão paciente quanto seu filho que está internado. Depois disso, comecei a olhar para os familiares com a mesma preocupação e atenção que olhava para o paciente em si, não só neste projeto como também em outros estágio que venho desenvolvendo dentro do meu curso de graduação. (A1)

... não cuidando apenas do prematuro em questão, mas da família do mesmo. (A2).

Sempre pensei que as mães que tinham bebês prematuros e com problemas físicos deveriam evitar falar sobre o assunto e principalmente estar com atenção voltada para o bebê, em todo o instante. As atividades, aos poucos, estão me mostrando que não é bem assim. Estou aprendendo que as mães precisam cuidar antes de tudo delas mesmas, ajuda a se acalmarem no acompanhamento do tratamento do bebê. (A3)

... a preocupação vai além do paciente em si, também visa o bem-estar da familia. (A4)

Estes aspectos apontados pelas alunas são particularmente importantes para a formação profissional, pois as habilidades requeridas para a Enfermagem Neonatal vão além do manejo dos equipamentos e da execução de procedimentos técnicos envolvidos no cuidado dos bebês pequenos, incluindo também, habilidades sociais para prover e promover apoio efetivo e comunicação com os familiares e equipe, conforme apontam Redshaw e Harris (1994).

Entretanto, o apoio afetivo, a comunicação com os usuários, familiares e equipe dever ser avaliada pois, estudo realizado por Santos et al. (1986) demonstra que os alunos de enfermagem recebem as informações teóricas necessárias sobre como deve se dar o relacionamento enfermeiro-paciente, porém não é ensinado o grau deste envolvimento, fato que pode prejudicar o relacionamento entre enfermeiropaciente.

Os autores abordam ainda, o aspecto de proteção que o aluno de enfermagem assume diante do paciente, o que pode influir negativamente em sua recuperação pois será criado um grau de dependência no relacionamento aluno-paciente. O aluno não deve se envolver a ponto de prejudicar o paciente, mas dever ser capaz de rir, chorar ou calar-se, sem esquecer que deve transmitir-lhe segurança.

Segundo Daniel (1983), apesar de não ser prudente envolver-se em excesso, isto não significa ficar alheio e impessoal, pois o profissional, bem como o paciente, sãos seres humanos com as mesmas necessidades básicas diferindo o grau de intensidade, dependência e qualidade dos problemas.

Percebemos que a vivência das alunas no projeto de extensão possibilitou o desenvolvimento de 
estratégias de comunicação e apoio aos pais dos bebês de risco, além de ensinar-lhes, gradualmente, como deve ser o apoio a esses pais, sem que este seja frio ou distante.

\section{Visão holística do cuidado}

O cuidado com o outro é uma preocupação inerente do ser humano. Porém, nos últimos tempos, esse cuidado tem se tornado muito coisificado e materialista. O profissional tem se preocupado apenas em cuidar do outro no que se refere a parte do corpo que está doente, esquecendo-se de analisar todos os outros sinais que o cliente pode demonstrar através das palavras, dos gestos e das atitudes.

Nesta perspectiva surge a filosofia holística que, segundo Boff (1999), é uma alternativa ao realismo materialista que busca respostas para enriquecer a visão superficial que a sociedade apresenta. $E$ isto significa percorrer um longo caminho de mudança de hábitos cotidianos, políticos, públicos, privados e culturais. Para o autor o cuidado está na constituição do ser humano e sem ele deixamos de ser humanos.

A filosofia holistica está presente na formação acadêmica do graduando de enfermagem em várias disciplinas, cuja vivência também foi possibilitada pelo projeto, ocasionando uma reflexão para uma possivel mudança na atitude do cuidado, tanto na vida profissional como na pessoal. Estas reflexões, apontadas pelas alunas, são citadas abaixo:

Compreendi a diferença do cuidado numa visão holística e numa visão mecanicista ... Pude aprender a ver a situação do lado do outro, do cliente, ou da familia do cliente. (A2)

Possibilitou ... uma visão holística onde há preocupação do indivíduo como um todo. (A4)

Hoje, próxima da vida profissional, posso avaliar que todas as dificuldades, todos os nãos e sins que ganhamos tem um significado muito maior, pois me fizeram acreditar que o cuidado com o ser humano não é uma simples operação matemática, ou uma sistemática de ações, mas sim envolve uma coisa muito mais ampl,a que só poderá ser melhor compreendida quando olhar mais para o próprio ser humano. (A5)

Esse aspecto apontado pelas graduandas é particularmente importante para a formação profissional pois atende aos carecimentos atuais da atenção à saúde, nos quais há uma ênfase na assistência integral, humanizada e preventiva, visando à qualidade de vida. Nesta perspectiva, o paradigma biotecnológico do pensar saúde é substituido pelo holismo, tendo como fundamentação o processo saúde-doença-cuidado.

Para reafirmar a importância deste aprendizado,
Nosseto (1997) afirma que a relação enfermeiropaciente tem que ser intersubjetiva, pois é nesta dimensão que o cuidado não se transforma em uma coisificação.

TEMA 2 - MELHORANDO O RELACIONAMENTO INTERPESSOAL E O DESENVOLVIMENTO DE HABILIDADES

O relacionamento interpessoal na enfermagem é de extrema importância para o cuidado do cliente. Algumas disciplinas da grade curricular da EERP-USP inserem este tema como um objetivo a ser alcançado na formação profissional, face a sua importância. Este tema é abordado por praticamente todas as alunas, possibilitando a análise de que elas incorporaram este aprendizado na sua formação, conforme mostram os relatos:

Melhoria no relacionamento interpessoal; pude aprender a ver a situação do lado do outro, do cliente, ou da família do cliente (...) Melhor desempenho dentro de grupos ... antes eu ficava esperando as coisas acontecerem, hoje vou atrás, procuro; tento resolver os problemas não só do grupo de pais, mas de todos os grupos em que estou inserida. (A2)

... a experiência está mudando aos poucos a minha maneira de lidar com as mães, principalmente. (A3)

Aumentou a minha facilidade de relação interpessoal com minhas colegas, com os funcionários do $\mathrm{HC}$ e a relação com as mães ... Facilitou o meu desempenho a o falar em público, na abordagem e argumentação dos pais para participação no grupo ... Propiciou o trabalho em grupo, onde as atividades são interrelacionadas, depende do trabalho do colega para dar continuidade, aumentando o senso da responsabilidade. (A4)

A recompensa deste trabalho é imediata, assim como as críticas também, é fácil perceber se a atividade está sendo agradável ou não e isto faz com que possamos aprender a entender as frustrações. (A5)

Segundo Daniel (1983), a aplicação de técnicas de relacionamento interpessoal faz com que a formação do aluno seja mais completa. $\mathrm{Na}$ assistência deve haver um esforço em harmonizar as qualidades individuais a fim de ter maior sensibilidade em relação aos próprios sentimentos e pensamentos, com o objetivo de reagir favoravelmente frente às necessidades do cliente.

A estratégia comunicacional inteligente é um ponto importante, pois através dela o profissional tem a arte de coordenar ações e alcançar os objetivos propostos. 
TEMA 3 - A ASSISTÊNCIA HOSPITALAR: PARA ALÉM DA DOENÇA

Através dos tempos, o hospital passou por transformações para atender aos carecimentos sociais articuladas à organização política, econômica e social de realidades concretas.

$\mathrm{Na}$ Inglaterra no século XIX, o hospital estava organizado com a finalidade de excluir da sociedade velhos e pobres, afastando-os da classe rica. Com a Revolução Industrial, a necessidade de promover a recuperação da força do trabalho torna o hospital um instrumento de cura, ou seja, para a recuperação da força do trabalho das indústrias (Foucault, 1981).

Mais recentemente, hospital tem sido visto como espaço não só de cura, centrado em doença, mas também de promoção à saúde, inserido na rede regionalizada e hierarquizada de serviços do sistema de saúde, na perspectiva do continuum da assistência. Portanto, as ações ai desenvolvidas não se restringem a recuperação do corpo anátomofisiológico ou cura, mas têm enfatizado também a assistência integral e preventiva, tendo como fundamentação o processo saúde-doença-cuidado, conforme citado anteriormente .

Essa nova visão, de certa forma, foi assimilada pelas alunas de enfermagem que passaram a entender o hospital como um ambiente onde outros procedimentos também podem ser utilizados, além da terapêutica medicamentosa e procedimentos invasivos, conforme apontam os relatos:

Apreendi o hospital como um lugar que se pode curar não só pela técnica ou pelo procedimento, seja ele invasivo ou não, mas pelo riso, por uma brincadeira de criança, por uma piada sem maldade, por um momento de reflexão. (A2)

Possibilitou outra visão do hospital, lugar onde se pode associar a cura, medicamentos e procedimentos rotinizados, com brincadeiras, diálogos e risos (...) Expandiu a minha visão sobre o papel do hospital que além de prestar assistência ao paciente proporciona intervenções com os familiares do enfermo. (A4)

Lima (1996) descreve as mudanças que ocorreram no modelo de assistência dirigida a criança hospitalizada. Antigamente, o atendimento era centrado no modelo clínico, hospitalar e altamente curativo. Este modelo tem como base a patologia, seus sinais e sintomas, e todo o esforço é feito no sentido de se conseguir um diagnóstico a fim da pronta instalação de medidas terapêuticas. Entretanto, a prática baseada na clínica mostrou-se insuficiente para atender às necessidades das crianças e de suas familias. Para responder a esta nova necessidade, 0 cuidado à criança passa a ser integralizado, abrangendo também sua familia, o qual é realizado por uma equipe multiprofissional utilizando-se de conhecimentos da Psicologia, Sociologia, Antropologia e Epidemiologia.

\section{TEMA 4 - ADQUIRINDO CONHECIMENTOS E VALORES}

\section{Adquirindo conhecimentos}

Entendemos que aprender vai além de estudar nos livros e ouvir lições orais; significa também adquirir nova forma de conduta e/ou modificar uma forma de conduta anterior.

Ainda na perspectiva do processo ensinoaprendizagem, Manzolli (1987) refere que o ensino é simplesmente uma palavra com valor de linguagem ordinária para expressar um conjunto de práticas distintas com o intuito de mudar crenças e valores. A autora também afirma que qualquer modificação sofrida nas crenças e valores dos individuos acarretam conseqüências práticas no mundo.

A participação das graduandas no projeto possibilitou transformação na postura profissional e pessoal, conforme demonstra os relatos:

Este projeto trouxe novos conhecimentos, não só específicos da área de neonatologia (...) A aproximação com as mães também com os outros familiares me proporcionou valores para os quais eu ainda não havia me valido enquanto profissional e também como pessoa. (A1)

Pude desenvolver leituras, obtive conhecimentos, os quais incorporei na minha formação profissional. (A2)

Aumentou o meu contato com trabalhos científicos sobre o assunto (...) Desenvolveu o meu senso de responsabilidade. Desenvolveu meu senso crítico sobre a percepção dos pais e o que um filho prematuro representa para a estrutura familiar. (A4)

Cabe ressaltar que além do desenvolvimento das atividades de intervenção junto às mães e aos pais dos bebês de risco, algumas alunas tiveram acesso a publicações científicas sobre temáticas pertinentes ao projeto, e também de outras pesquisas em andamento no Grupo de Estudo em Enfermagem Neonatal, colaborando em alguns levantamentos bibliográficos. Este grupo é constituído por docentes, enfermeiros de serviço, alunos de graduação e pósgraduação.

\section{Estimulando a criatividade: aceitando o desafio}

Os relatos a seguir elucidam esse sub- tema: Claro que tivemos experiências ruins durante o período que aqui estou, mas penso que são 
fundamentais para entender que a enfermagem é uma profissão de altos e baixos como outra qualquer e que cabe ao profissional saber lidar com todas as intercorrências, sempre se preocupando com o bemestar do paciente e da família e ter criatividade profissional para resolvê-las. (A1)

Estimulou minha criatividade; programava uma atividade para determinado número de pessoas e, na hora, comparecia muito menor do que eu esperava, então tinha que pensar rápido, não podia passar o dia sem desenvolver alguma atividade. (A2)

Melhorei a minha improvisação, aumentando a minha criatividade e desibinição. (A4)

Merece destaque o fato da vivência no programa de extensão de serviços à comunidade ter contribuido para o desenvolvimento da criatividade nas alunas de enfermagem, o que vem de encontro às recomendações de Manzolli (1987, p. 33):

É necessário investigar formas de como reforçar a autoconfiança do aluno de Enfermagem a ser criativo; motivá-lo a usar mais e melhor o seu potencial criativo; levá-lo a ser mais flexivel no recebimento e posicionamento de idéias, nos pareceres de terceiros; torná-lo mais curioso e mais atento para os desafios da vida; estimular uma atitude de 'descontentamento construtivo' para o cotidiano; estimular a capacidade do aluno, de desenvolver idéias originais de qualidade, que conduzem à solução criativa dos problemas; ajudá-lo a se conscientizar a respeito da importância do esforço criativo nos dias atuais na sua profissão, nas pesquisas cientificas, na vida pessoal em geral e na saúde em especial. Desenvolver o espírito crítico, um dos objetivos gerais do todo o curso superior, imprescindivel para a formação de profissionais liberais.

A responsabilidade citada por uma das alunas vem de encontro a outro aspecto que a universidade apresenta: participar da formação humana do ser estudante.

De acordo com Jorge (1997), a responsabilidade significa o aluno ir em busca com perseverança para conquistar seus ideais e autonomia. Neste âmbito, é fundamental para o aluno ter ação no caminho escolhido por ele, pois seu sucesso depende dele. Da análise de desempenho e compromisso das alunas na execução das atividades operacionais do projeto, percebemos o aumento crescente do senso de responsabilidade profissional e o amadurecimento emocional.

\section{CONSIDERAÇÕES FINAIS}

Pelos resultados obtidos apreendemos que a inserção das alunas de graduação em um projeto de extensão de serviços à comunidade, envolvendo o desenvolvimento de atividades lúdicas e de lazer junto aos pais de bebês de risco hospitalizados, ampliou as possibilidades de estratégias pedagógicas para a formação profissional na área de Enfermagem. Urge portanto, expandir essa experiência nas diversas disciplinas profissionalizantes da grade curricular, contribuindo com a formação profissional de enfermeiros competentes não só tecnicamente, mas sensiveis a humanização e integralidade da assistência, de modo a se constituírem em atores sociais no processo de transformação do modelo de atenção vigente nos serviços de saúde.

\section{REFERÊNCIAS BIBLIOGRÁFICAS}

ALMEIDA, M. C. P. Prática de enfermagem na atenção primária de saúde: a experiência do Departamento de Enfermagem Materno-Infantil e Saúde Pública da Escola de Enfermagem de Ribeirão Preto - Universidade de São Paulo-Brasil. julho 2000, 21 p. digital.

BARDIN, L. Análise de conteúdo. Lisboa: Edições 70, 1977.

BOFF, L. Saber cuidar: ética do humano - compaixão pela terra. Petrópolis: Vozes, 1999.

BRUNHEROTTI, M.R. et al. Lazer para os pais de bebês de risco: a experiência junto ao Hospital das Clínicas de Ribeirão Preto. Rev. Bras. Enferm., v.53, n. 3, p. 435-42, 2000.

COSTA, F.N.A. Pesquisando para ensinar: a "práxis" de ensino de enfermagem. Ribeirão Preto, 1993. $152 \mathrm{f}$. Dissertação (Mestrado) - Escola de Enfermagem de Ribeirão Preto, Universidade de São Paulo.

DANIEL, L.F. Atitudes interpessoais em enfermagem. São Paulo: EPU, 1983.

FOUCAUL, M. Microfisica do poder. 2.ed. Rio de Janeiro: Graal, 1981.

JORGE, A.S. Rendimento acadêmico de estudantes de enfermagem relacionado com niveis de ansiedade, expectativa e atribuição de causalidade. Ribeirão Preto,1997, 84 f. Dissertação (Mestrado) - Escola de Enfermagem de Ribeirão Preto, Universidade de São Paulo.

JORGE, M.S.B. Indo em busca do seu plano de vida: a trajetória do estudante universitário. Florianópolis: PapaLivro, 1997.

LIMA, R.A.G. Criança hospitalizada: a construção da assistência integral. Ribeirão Preto, 1996. 254 f. Tese (Doutorado) - Escola de Enfermagem de Ribeirão Preto, Universidade de São Paulo.

LIMA, R.A.G. A enfermagem na assistência à criança com câncer. São Paulo: AB, 1995. 109 p. 
MANZOLLI, M.C. Relacionamento em enfermagem: aspectos psicobiológicos. São Paulo: Sarvier, 1987.

NOSSETO, N.M.C. Expectativas en el ingresso a Enfermaria. Limites y Posibilidades. Temas de Enfermaria Actualizados, v. 5, n. 24, p. 30, 1997.

REDSHAW, M.E.; HARRIS, A. Training and education for nurses working in neonatal care. Journal of Advanced Nursing, v. 21, n. 2, p. 1023-29, 1994.

SANTOS, R. et al. Envolvimento emocional do acadêmico de enfermagem com o paciente: reflexos dessa experiência na vida futura do profissional. Rev. Bras.
Enferm., v. 39, n. 1, p. 61-66, 1986.

SCOCHI, C.G.S. A organização do trabalho e a prática de enfermagem em unidades neonatais de diferentes niveis de complexidade. Regional de Ribeirão Preto ERSA-50. Ribeirão Preto, 1996. 213 f. Tese (Doutorado) - Escola de Enfermagem de Ribeirão Preto, Universidade de São Paulo.

SCOCHI, C.G.S. et al. O apoio aos pais de bebês em berçário de risco: uma proposta de intervenção de enfermagem. In: CONGRESSO BRASILEIRO DE ENFERMAGEM 51., 1999, Florianópolis - SC. Livro de Resumos... Florianópolis: ABEn, 1999. 